\title{
Cyclic Fatigue Life Assessment of a Newer Heat-treated Reciprocating NiTi File in a 90-degree Canal Curvature
}

\author{
Sahil Chanian ${ }^{1}$, Sathish Sundar ${ }^{2}$, Nandini Suresh $^{3}$, Velmurugan Natanasabapathy ${ }^{4}$
}

\begin{abstract}
Aim: The purpose of this study was to compare the cyclic fatigue resistance WaveOne Gold and WaveOne files in a reciprocating motion. Materials and methods: A total of 24 new rotary WaveOne Gold (ISO size $=25$, taper $=0.07$, length $=25 \mathrm{~mm}$ ) and WaveOne files (ISO size $=25$, taper $=0.08$, length $=25 \mathrm{~mm}$ ) were selected and divided into 2 groups ( $n=12$ each). A cyclic fatigue-testing device was fabricated with a 90 -degree angle of curvature and a $5 \mathrm{~mm}$ radius. All instruments were reciprocated until fracture occurred. The time was taken for each instrument to fracture, and the length of the broken fragments was recorded. All the fractured files were analyzed under a scanning electron microscope to detect the mode of fracture. The Kolmogorov-Smirnov test was used to assess the normality of sample distribution, and statistical analysis was performed using the independent sample $t$ test.

Results: The time taken for the instruments of WaveOne Gold group to fail under cyclic loading was significantly longer compared with the WaveOne group $(p<0.001)$. Scanning electron microscopic observations showed that the instruments of all groups had undergone a ductile mode of fracture. The length of the fractured segments was between 1.5 and $5 \mathrm{~mm}$, which was statistically significant among the experimental groups. Conclusion: WaveOne Gold instruments showed a significantly higher cyclic fatigue resistance compared to WaveOne in a reciprocating motion. Keywords: Cyclic fatigue, Nickel-titanium, Reciprocating files, WaveOne, WaveOne Gold. Journal of Operative Dentistry and Endodontics (2019): 10.5005/jp-journals-10047-0065
\end{abstract}

\section{INTRODUCTION}

Nickel-titanium (NiTi) alloy called nitinol was introduced in the field of endodontics and has tremendously evolved since its inception. Though there are a lot of advancements in the file design and metallurgy, instrument separation remains an endodontist's nightmare. Fracture of rotary $\mathrm{NiTi}$ instruments may take place because of torsion and/or flexion.

Cyclic fatigue occurs when an instrument continues to rotate freely in a curvature. Compression and tension cycles are generated until a fracture occurs at the point of maximum flexure. ${ }^{1}$ The cyclic fatigue life of a file is influenced by various factors including flexibility, diameter, mass, design, and the quality of manufacturing of the NiTi files. The cyclic fatigue of the file is inversely proportional to the file diameter and directly proportional to the flexibility of the instrument. ${ }^{2}$ The principle of NiTi file motion is another factor that influences the cyclic fatigue of the file. Yared proposed a new approach using a single ProTaper F2 instrument in a reciprocating movement for cleaning and shaping, which has revolutionized the cyclic fatigue resistance of NiTi files. ${ }^{3}$ Based on this concept, two single-file systems namely WaveOne and Reciproc were introduced.

WaveOne is a NiTi instrument that advocates the reciprocation concept. The reciprocal motion would reduce the cyclic stress by periodically reversing the rotation $\left(170^{\circ}\right.$ counter-clockwise, then $50^{\circ}$ clockwise rotation for WaveOne) of the file. Recently, WaveOne Gold has been introduced. It has the reciprocating motion of the WaveOne file with modified dimensions. The file is a parallelogram in cross-section with two cutting edges and an off-center design. The files are manufactured with a gold heat treatment procedure, which is done manually by heating the file initially and then cooling slowly. It is different from M-Wire technology which undergoes premanufacturing heat treatment. It has been proved that this new heat treatment leads to improved cyclic fatigue life.

\begin{abstract}
${ }^{1-4}$ Department of Conservative Dentistry and Endodontics, Faculty of Dental Sciences, Meenakshi Academy of Higher Education and Research, Meenakshi Ammal Dental College, Chennai, Tamil Nadu, India

Corresponding Author: Sathish Sundar, Department of Conservative Dentistry and Endodontics, Faculty of Dental Sciences, Meenakshi Academy of Higher Education and Research, Meenakshi Ammal Dental College, Chennai, Tamil Nadu, India, Phone: +91 9884511763, e-mail: sathsundar87@gmail.com

How to cite this article: Chanian S, Sundar S, et al. Cyclic Fatigue Life Assessment of a Newer Heat-treated Reciprocating NiTi File in a 90-degree Canal Curvature. J Oper Dent Endod 2019;4(1):6-9.
\end{abstract}

Source of support: Nil

Conflict of interest: None

Özyürek ${ }^{4}$ tested the cyclic fatigue of WaveOne, Reciproc, and WaveOne Gold in a 60-degree canal curvature and observed that WaveOne Gold file system had better cyclic fatigue resistance as compared to WaveOne and Reciproc R25 file instruments. However, curvatures higher than 60 degrees are encountered in endodontic practice, and whether these instruments actually sustain the forces generated in such severe canal curvatures have not been analyzed.

There are no earlier studies comparing WaveOne and WaveOne Gold reciprocating files in a 90-degree curvature. The aim of this study was to assess the cyclic fatigue life of WaveOne Gold and WaveOne files using a dynamic model in a 90-degree canal curvature.

\section{Materials and Methods}

\section{Sample Selection}

A total of 12 new reciprocating WaveOne Gold (Dentsply, Tulsa Dental Specialties, USA) (ISO tip size $=25$, taper 0.07 , length $=25 \mathrm{~mm}$ ) 
and 12 new WaveOne (Dentsply Maillefer, Ballaigues, Switzerland) (ISO tip size $=25$, taper 0.08 , length $=25 \mathrm{~mm}$ ) files were selected. Instruments were checked under an optical stereomicroscope (Zoom Stereo Binocular Microscope, Hicksville, NY, USA); with $20 \times$ magnification for any signs of deformation. Instruments with deformation were excluded from this study.

\section{Cyclic Fatigue Testing Device}

A custom fabricated dynamic model was used to test the fatigue resistance of the WaveOne Gold and WaveOne files (Fig. 1). This apparatus had a main metal frame made of iron with an artificial canal system and custom-made handpiece support attached over it. The simulated root canal system consisted of two adjustable brass frames that can accommodate any instrument to its taper and exact size. It was built with a 90-degree angle of curvature. The curvature initiated at $5 \mathrm{~mm}$ from the tip of the canal. The whole set of platform along with the handpiece was powered by the electric motor system, reproducing the pecking motion, with $2.5 \mathrm{~mm} /$ minute each (forward or backward) direction. This movement took place at a speed of 1 cycle per second.

\section{Cyclic Fatigue Test}

Twenty-four samples were randomly divided into two groups each ( $n=12$ ) according to the type of instrument used.

\section{Group I}

WaveOne Gold files were used in a reciprocating motion set at WaveOne Gold setting in the X-Smart Plus motor (X-Smart Plus, Dentsply, Ballaigues, Switzerland) according to manufacturer's instructions.

\section{Group II}

WaveOne files were used in a reciprocating motion set at the WaveOne setting in the X-Smart Plus motor (X-Smart Plus, Dentsply, Ballaigues, Switzerland) according to manufacturer's instructions.

Glycerin was used as a lubricant during instrumentation. Instruments were allowed to reciprocate until they fractured. The cyclic fatigue testing was done under a dental operating microscope at $25 \times$ magnification to precisely determine the time to fracture. All the files were tested by one operator while the second operator simultaneously recorded the time using a stopwatch.

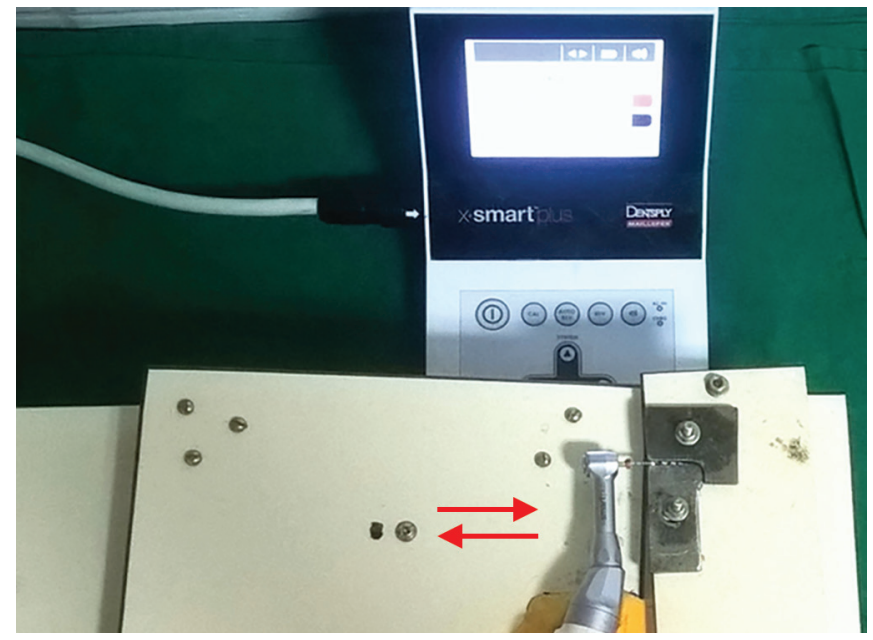

Fig. 1: Dynamic model for cyclic fatigue testing (red lines: indicating the pecking motion)
The length of the fractured fragments was measured using a digital Vernier caliper (Aerospace Digimatic Vernier Caliper, 0-150 mm).

\section{Scanning Electron Microscopic Analysis}

Five samples from each group were randomly selected. The examination of fractured surfaces of the files was done under a scanning electron microscope (FEI QUANTA 200 FEG, Hillsboro, OR, USA) at $200 \times-1,500 \times$ magnification to determine the characteristics and mode of fracture.

\section{Statistical Analysis}

The mean and standard deviation of the time to fracture, and the length of the fractured fragment was calculated for all the experimental groups. The Kolmogorov-Smirnov test and ShapiroWilk test were used to access the normality. The intergroup analysis was performed using an independent sample $t$ test (Software SPSS VERSION 16) for both the time to fracture and the length of the fractured segment. A $p$ value of $<0.05$ was considered statistically significant.

\section{Results}

The mean time to fracture for WaveOne Gold and WaveOne was 268.33 seconds and 210.92 seconds, respectively. There was a statistically significant difference between the WaveOne Gold and WaveOne groups in reciprocating motion with regards to time taken to fracture (Table 1).

The mean length of the fractured segment of WaveOne Gold and WaveOne is $2.7033 \mathrm{~mm}$ and $3.6517 \mathrm{~mm}$, respectively. Statistically, a significant difference was observed between the two groups pertaining to the length of the fractured fragment (Table 1).

\section{Scanning Electron Microscopic Analysis Results}

Scanning electron microscopic analysis of fractured surfaces of all the samples in both the groups revealed craters like formation along with numerous valleys, dimples, and microbubbles (Fig. 2). These fracture pattern features indicate that the instrument has undergone a ductile mode of fracture, which is predominantly observed in cyclic fatigue failure.

\section{Discussion}

Various factors affect the cyclic fatigue of an instrument rotating in the root canal. Every rotation inside a curved canal causes an instrument to endure one complete tension-compression stress cycle. The more severe the curvature, the more stresses are concentrated on the rotary file. It has been observed that the metallurgy ${ }^{5}$ and reciprocating motion plays a pivotal role in cyclic fatigue of file and hence paving the way for the introduction of newer endodontic files. Previous studies have shown that reciprocating motion has superior resistance to cyclic fatigue compared to the rotation motion. ${ }^{6-8}$

WaveOne file is a single file reciprocating system, which uses a single instrument made of $\mathrm{M}$-Wire technology to clean and shape the entire canal. Elsaka et al. ${ }^{9}$ found that the WaveOne Primary file had greater resistance to cyclic fatigue than OneShape file in a 90-degree canal curvature.

A unique thermal processing and post-machining procedure generates a new super-metal that is commercially termed as goldwire. The heat treatment effects the transformation temperatures (austenitic start and austenitic finish), and this improves the 
Table 1: Descriptive statistics of time taken to fracture and the mean length of the fractured segment of WaveOne Gold and WaveOne files

\begin{tabular}{|c|c|c|c|c|c|}
\hline Group & $N$ & $\begin{array}{l}\text { Mean time to fracture } \\
\text { and std deviation (sec) }\end{array}$ & $p$ value & $\begin{array}{l}\text { Mean length of the fragment } \\
\text { and std deviation }(\mathrm{mm})\end{array}$ & $p$ value \\
\hline WaveOne Gold & 12 & $268.33 \pm 61.18$ & 0.015 & $2.7033 \pm 0.76$ & 0.022 \\
\hline WaveOne & 12 & $210.92 \pm 44.05$ & & $3.6517 \pm 1.10$ & \\
\hline
\end{tabular}
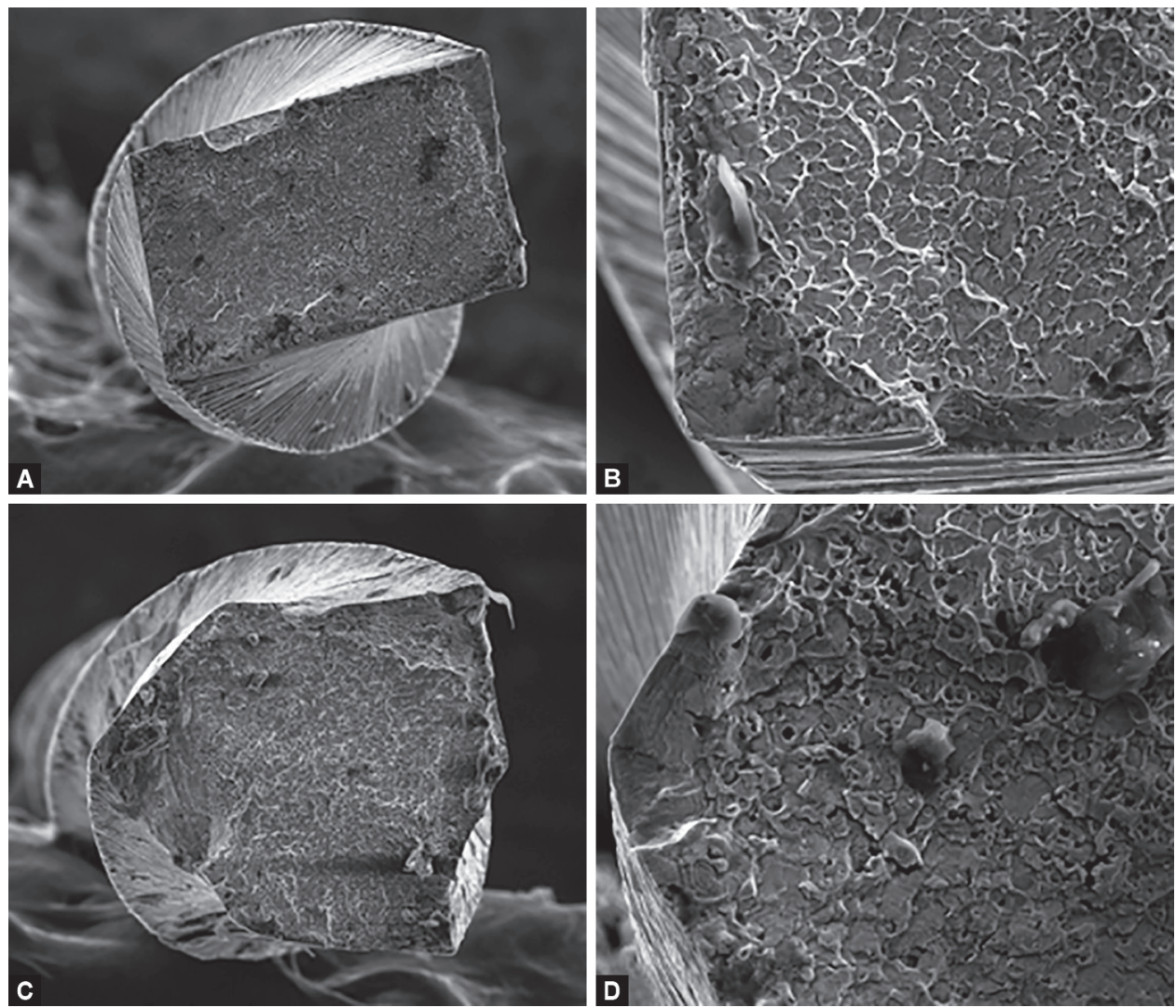

Figs 2A to D: SEM images of cross-section of files. (A) WaveOne Gold at 220x; (B) WaveOne Gold at 1000x; (C) WaveOne at 220x; (D) WaveOne at 1000x

instrument properties. Özyürek ${ }^{4}$ and Topçuoğlu et al. ${ }^{10}$ compared the cyclic fatigue life of WaveOne Gold and WaveOne in a 60-degree curvature and an S-shaped double curvature respectively; they proved that WaveOne Gold has better cyclic fatigue resistance as compared to WaveOne file. Hence, WaveOne Gold and WaveOne have been chosen for our study.

Earlier studies pertaining to cyclic fatigue have been conducted in various canal curvatures like $30,{ }^{11} 60,{ }^{12,13}$ and $90^{14}$ degrees. By increasing the severity of curvature, more pressure is induced in the file. The behavior of these heat-treated gold files is not studied in a severe curvature model. Hence, a 90-degree curvature was chosen for this study. In most of the studies, the center of curvature was between $5 \mathrm{~mm}$ and $7 \mathrm{~mm}$ from the tip of the instrument. In this study, a custom made artificial canal was fabricated with a 60-degree curvature with an of curvature at $5 \mathrm{~mm}$ from the instrument tip.

In our study, it was observed that WaveOne Gold had better cyclic fatigue resistance than WaveOne. The WaveOne Gold file performed 1.3 times better than the WaveOne file (90-degree curvature). Özyürek ${ }^{6}$ et al. in their study found out the WaveOne Gold file had 1.4 times more cyclic fatigue resistance when compared with wave one ( $60^{\circ}$ curvature). The probable reason for WaveOne Gold to have a better cyclic fatigue life in severe acute canal curvatures might be because of high $A_{f}$ (Austenite finish) value and a 2-stage transformation behavior. ${ }^{6}$
Hieawy et al. ${ }^{15}$ showed that the differential scanning calorimeter results of gold wire instruments had a 2-stage specific transformation behavior, indicating that reverse transformation of the alloy passes through the intermediated R-phase. Interestingly, the metallurgical characteristics of gold wire files had not only a 2-stage specific transformation behavior but also had high $A_{f}$ temperatures. In a 2-stage $\mathrm{A}-\mathrm{R}-\mathrm{M}$ transformation, due to additional heat treatment, finely dispersed $\mathrm{Ti}_{3} \mathrm{Ni}_{4}$ precipitates are created in the austenitic matrix. The presence of these $\mathrm{Ti}_{3} \mathrm{Ni}_{4}$ particles favors the formation of R-phase which is more resistant to cyclic fatigue. ${ }^{7}$

On longitudinal analysis of the files, it was observed that WaveOne Gold had seven flutes and WaveOne had nine flutes. Increasing the number of flutes increases the concentration points during flexion, which might lead to increased cyclic fatigue and fracture 3. The pitch of WaveOne Gold and WaveOne files is variable over the active portion of both the files. The WaveOne Gold has a taper of 0.07 whereas the WaveOne has an apical taper of 0.08 , which may provide more flexibility to the WaveOne Gold as compared to WaveOne.

The limitations of this laboratory study are that the various contributing factors for the fatigue behavior of NiTi rotary files are not considered (that is the material properties and design and dimensions of each file, which are specific to each brand tested) and 
cannot be completely standardized. This makes it difficult to quantify the effect of a single variable on fatigue behavior. Differential scanning calorimeter and the $A_{\mathrm{f}}$ values were not calculated in the present study. Further research in this area is needed in order to consider all the parameters of fatigue testing.

\section{ConcLusion}

Within the limitations of this study, WaveOne Gold rotary endodontic files were more resistant to cyclic fatigue in a dynamic reciprocating motion when compared with WaveOne files in a 90-degree canal curvature. Further studies comparing the torsional stress are needed for an evidence-based superiority of WaveOne Gold over WaveOne files.

\section{ACKnOWLedgment}

Authors sincerely thank Mr Srinivasan from the Indian Institute of Technology (IIT), Chennai for his technical assistance pertaining to the scanning electron microscope analysis.

\section{References}

1. Sattapan B, Nervo GJ, et al. Defects in rotary nickel-titanium files after clinical use. J Endod 2000;26:161-165. DOI: 10.1097/00004770200003000-00008.

2. McSpadden JT. Mastering Endodontic Instrumentation: mastering instrument designs. 1st ed., Cloudland Institute; 2007. p. 52-58.

3. Yared G. Canal preparation using only one $\mathrm{Ni}-\mathrm{Ti}$ rotary instrument: preliminary observations. Int Endod J 2008;41:339-344. DOI: 10.1111/j.1365-2591.2007.01351.x.

4. Özyürek T. Cyclic Fatigue Resistance of Reciproc, WaveOne, and WaveOne Gold Nickel-Titanium Instruments. J Endod 2016;42: 1536-1539. DOI: 10.1016/j.joen.2016.06.019.
5. Otsuka K, Ren X.Physical metallurgy of Ti-Ni-based shape memoryalloys. Prog Mater Sci 2005;50:511-678. DOI: 10.1016/j.pmatsci.2004.10.001.

6. Lopes HP, Gambarra-Soares T, et al. Comparison of the Mechanical Properties of Rotary Instruments Made of Conventional NickelTitanium Wire, M-Wire, or Nickel Titanium Alloy in R-Phase. J Endod 2013;39:516-520. DOI: 10.1016/j.joen.2012.12.006.

7. Dagna A, Poggio C, et al. Cyclic fatigue resistance of OneShape, Reciproc, and WaveOne: An in vitro comparative study. J Conserv Dent 2014;17:250-254. DOI: 10.4103/0972-0707.131788.

8. Sekar V, Kumar R, et al. Assessment of the role of cross section on fatigue resistance of rotary files when used in reciprocation. Eur $J$ Dent 2016;10:541-545. DOI: 10.4103/1305-7456.195171.

9. Elsaka SE, Elnaghy AM. Cyclic fatigue resistance of OneShape and WaveOne instruments using different angles of curvature. Dent Mater J 2015;34:358-363. DOI: 10.4012/dmj.2014-252.

10. Topçuoğlu HS, Düzgün S, et al. Laboratory Comparison of Cyclic Fatigue Resistance of WaveOne Gold, Reciproc and WaveOne Files in Canals With a Double Curvature. Int Endod J 2017;50:713-717. DOI: 10.1111/iej.12674.

11. Ferreira F, Adeodato C, et al. Movement Kinematics and Cyclic Fatigue of NiTi Rotary Instruments: A Systematic Review. Int Endod J 2017;50:143-152. DOI: 10.1111/iej.12613.

12. Vadhana S, Saravana Karthikeyan B, et al. Cyclic fatigue resistance of $\mathrm{RaCe}$ and Mtwo rotary files in continuous rotation and reciprocating motion. J Endod 2014;40:995-999. DOI: 10.1016/j.joen.2013.12.010.

13. Karatas $\mathrm{E}$, Arslan $\mathrm{H}$, et al. Effect of movement kinematics on the cyclic fatigue resistance of nickel-titanium instruments. Int Endod J 2016;49:361-364. DOI: 10.1111/iej.12453.

14. Johnson E, Lloyd A, et al. Comparison between a novel nickeltitanium alloy and 508 nitinol on the cyclic fatigue life of ProFile 25/.04 rotary instruments. J Endod 2008;34:1406-1409. DOI: 10.1016/ j.joen.2008.07.029.

15. Hieawy A, Haapasalo M, et al. Phase Transformation Behavior and Resistance to Bending and Cyclic Fatigue of ProTaper Gold and ProTaper Universal Instruments. J Endod 2015;41:1134-1138. DOI: 10.1016/j.joen.2015.02.030. 